\title{
Paideusis
}

\section{Conceptual Finesse}

\section{Robin Barrow}

Volume 1, Number 1, 1987

URI: https://id.erudit.org/iderudit/1071142ar

DOI: https://doi.org/10.7202/1071142ar

See table of contents

Publisher(s)

Canadian Philosophy of Education Society

ISSN

0838-4517 (print)

1916-0348 (digital)

Explore this journal

Cite this article

Barrow, R. (1987). Conceptual Finesse. Paideusis, 1(1), 3-12

https://doi.org/10.7202/1071142ar

(C) Robin Barrow, 1987

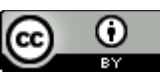

This document is protected by copyright law. Use of the services of Erudit (including reproduction) is subject to its terms and conditions, which can be viewed online.

https://apropos.erudit.org/en/users/policy-on-use/ 


\section{Conceptual Finesse}

\section{Robin Barrow, Simon Fraser University}

The not distinguishing where things should be distinguished, and the not confounding where things should be confounded, is the cause of all the mistakes in the world.

John Selden

In attempting to delineate the concept of conceptual finesse, I am partly responding to a suggestion made by Robert Dearden, ${ }^{1}$ and partly pursuing a particular line of thought on the nature and practical value of conceptual analysis in general. ${ }^{2}$ But it should be said that the outset that, regardless of my views on conceptualization in general, I recognize that in this instance my account of the meaning of "conceptual finesse" is largely stipulative. The phrase is not one that is in common use, and, in defining it and providing the label, I am seeking to locate and describe what seems to me to be a useful human attribute and, more specifically, a useful notion to focus on in the context of education. In view of the latter point, I shall conclude the paper with some tentative remarks on ways of developing conceptual finesse in schools.

It is clear, I think, that providing a definition in terms of a verbally synonymous phrase does not necessarily amount to offering an analysis of the concept. To say, for example, that the "creative act" is one that "engenders a feeling of effective surprise" does not help to explicate the idea of creativity, since the definition is as obscure as the original terms. Nonetheless, I shall start on the purely verbal level by observing that the phrase "having conceptual finesse" is dispositional (by which I mean that it relates to a temperament or usual frame of mind), and refers both to an ability and a desire or inclination. More specifically, one who has conceptual finesse is one who, in general, has both the desire and the ability to make fine discriminations in conceptual matters. That being so, such a person will have an armoury of clear and specific concepts at his disposal. ${ }^{3}$ Clearly, many experts, such as physicists, have such a capacity in relation to their subject, and also the desire and ability to make further fine discriminations in their area. But $I$ wish to write into the meaning of this phrase the additional point that the ability in ques- 
tion need not be confined to one or even a few special fields. A person with conceptual finesse, therefore has this tendency towards fine discrimination in relation to such perennial objects of human interest as politics, morality, interpersonal relations, love, parenthood, art and education or, simply, the stuff of daily life as distinct from the stuff of a developed academic discipline.

One further verbal point should be made. Any association with the idea of finessing at bridge, with its implications of deception and figurative sleight of hand, should be resisted. The word "finesse" is here supposed to convey only ideas of subtlety, deftness, and precision. As a consequence of these connotations, the phrase "conceptual finesse" is clearly normative.

At the verbal level, then, $I$ would define a person with conceptual finesse as one who has a set of finely discriminated, relatively specific concepts in relation to the stuff of life, and who has both the inclination and the ability to make further such fine distinctions as the occasion demands.

Conceptual finesse involves, as a phrase like "fine discrimination" may be taken to imply, specific concepts, which are to be distinguished from clear concepts. I might have clear conceptions of, say, love and hate, or progressive and traditional teaching styles, but if my concepts, though clear, are all of this broad type, then I lack conceptual finesse. Emphasis on a term such as discrimination, in explaining conceptual finesse, deliberately implies the breaking down of general concepts such as animal into more specific distinctions between animals. The person with conceptual finesse, therefore, thinks about human relations, not only in clear terms, but also in terms of relatively specific concepts-not just with a clear idea of friendship, but with clear and specific ideas of different types of friendship. There is, of course, no specifically quantifiable answer to such questions as "how specific" or "how many specific concepts" are required. One has greater conceptual finesse, in this respect, to the extent that one has more, intelligible, specific concepts. 4

This raises the question of the value of relatively specific concepts. Is it obviously desirable to think in terms of several species of friendship, rather than in terms of the generic friendship, assuming one is equally clear in either case? If so, why? I think to some extent this may be a contingent matter, depending on the state of the world and man's thinking. Aristotle, for example, has generally been admired for being a great categorizer and for bringing a host of specifics under a more general heading-for seeing, so to speak, that many seemingly different creatures are in fact all animals, or that a wide variety of human relationships are at one in being instances of friendship. ${ }^{5}$ Clearly, that is a most useful ability. To understand our world, one thing we have to do is organize it, recognizing 
similarity in apparent diversity. But we also need to be able to detect differences. It seems to me that, whereas in Aristotle's time a priority was to structure our understanding in terms of general categories, a very real danger that we face today is that people fail to look for and see important distinctions.

Argument in relation to the stuff of life, I would suggest, too often proceeds in terms of focusing on similarities rather than attempting to differentiate between things. For example, state organization that leads to poverty is classified by some as an instance of violence, as is hitting someone on the head. And so it may be, if "violence" is understood as a very broad term. But that is on a par with saying that snakes and ducks are both animals. So they are, but once you know that, to fail to see the differences between them could prove dangerous. The question of importance in relation to the violence example becomes are some forms of violence preferable or more excusable than others. That question is avoided by noting similarities in order to bring different activities under one broad heading. We need to develop the habit of noting differences, in order to be able to consider whether they are material differences in respect of the general categorization. Granted that both the state and individual thugs may be said to engage in violence, what are the differences between these species of violence, and are they such as to warrant us taking a different attitude to either one?

This tendency to think in general categories and to avoid the task of looking for possibly material differences between more specific concepts is quite common in education. It lies behind such practices as wanting to see everything in terms of skills, talking about general abilities such as critical thinking, castigating all forms of influence as indoctrination, and trying to lay down general rules for curriculum design without reference to varying subject matter and context. Educational discourse would surely be the better for more concern for discerning differences and for working with a repertoire of more specific concepts-for considering, for example, whether some of the skills involved in interpersonal relations, if it is correct to call them skills at all, are not so different in kind from various motor skills, or even intellectual skills, as to make it highly misleading to emphasize their broad generic similarity by referring to them as skills at all. 6

In addition to having a stock of relatively specific concepts, a person with "conceptual finesse" obviously has to conceptualize or analyze concepts well. I should therefore briefly make it clear what I understand by satisfactory conceptualization. Good conceptualization involves meeting four criteria: the concept in question should be clearly articulated, fully articulated, internally coherent, and it should only carry entailments that the individual entertaining or publicly analyzing the concept recognizes and can accept. The clarity 
criterion refers to verbal clarity. One's understanding or account of, say, indoctrination, must not be couched in terms that are equivocal, ambignous, or opaque. The fullness criterion refers to the further conceptual clarity of ideas introduced in the attempt to explain the initial concept. If, for example, part of my account of indoctrination involves reference to "the intention to close the mind," there is no verbal obscurity here, but there is a new conceptual problem: what exactly constitutes "the intention to close the mind"? If that question is not answered, the account of indoctrination is not full enough. The internal coherence criterion refers obviously enough to the requirement that the concept in question shall not involve such things a logical contradiction. The entailment criterion requires that the concept shall fit into one's wider system of beliefs. If, for example, I equate indoctrination with influence, then $I$ must recognize that it cannot be regarded as necessarily a bad thing, and it must be the case that I do not go around assuming that it is necessarily a bad thing.

It will be noted that, on this view, conceptual analysis and having adequate concepts are not verbal matters at all. There are questions to be asked about the word "indoctrination" with what I call "influence," then, provided that they can explain it clearly, fully and coherently, and accept the entailments, I should call it a satisfactory conception, even though it is not mine. The question of whether it is correct, I regard as meaningless, except on the verbal level. I can, perhaps, say that it is an incorrect use of the word "indoctrination." But I cannot say it is an incorrect conception. It is his conception-it is the idea he is concerned with-and that is all there is to it. All I can reasonably require is that the idea be clearly, fully, coherently articulated and its entailments recognized-and perhaps relabelled for our mutual convenience.

Let me elaborate. Insofar as a person entertains an idea so as to meet the four criteria, he has a concept in a full and proper sense. One may ask various questions about it. Does it, for example, correspond to anything in the physical world, or is it, like the unicorn, a concept of something imaginary? Do other people have this concept, in the sense of also entertaining this idea? Or is it perhaps a novel idea or simply an idea of no interest to anyone else as, for example, the concept of chivalry in our own times? Does it correspond to typical use? While one can ask these questions, one cannot meaningfully ask whether the person's concept is true or false, correct or incorrect, any more than one can ask whether my feeling of pain is true or false. I feel pain, and there is the end of it. I have this concept and that is that.

The question that this view gives rise to is: does this give carte blanche for people to entertain any idea they like? Surely, it does 
not. For there are powerful logical restraints set, in particular, by the coherence and entailment criteria. I cannot, literally cannot, conceive of squared circles, married bachelors and four-sided triangles. Of course, I can conceive of a four-sided figure and call it "a foursided triangle." But for that to be coherent I must be conceiving of what others call a square and my mistake is verbal rather than conceptual. But I cannot, logically cannot, conceive of the thing that is generally called a triangle and attribute four sides to it. And given my wider system of beliefs there are hundreds of things that I cannot coherently conceive in relation to, say, morality and religion. So I can certainly be criticized for my conceptions, but, at least so far, only in terms of the four criteria: my notion of a married bachelor is incoherent, rather than false; my notion of intelligence as "quickness of understanding" is insufficiently full, rather than false; my notion of education according to interest is insufficiently clear, being ambiguous, rather than false; and by notion of vocational education will not square with my notion of education, rather than being false.

The more interesting question is whether physical reality can set constraints on legitimate conceptions, and here $I$ think the answer is "no." I am bound to think this given that I do not think it makes sense to say that a concept can be false or incorrect, since evidently people can be mistaken about physical reality.

One can, of course make mistakes about, say, mountains or cows, such as believing that all mountains are hollow or that cows can run at 100 m.p.h. The question is whether these are conceptual mistakes, and I maintain that they are not. The conceptual question is essentially what counts as an $X$, what constitutes an $X$, or what are the defining characteristics of an $X$. And that surely is determined by people. Perhaps, indeed, ideally it should be rephrased as "what is to count as an X?" or "what are to be the defining characteristics of X?" For is not all analysis, if not prescriptive, at any rate a matter of preferred definition? And is conceptualization not at bottom a creative business?

Now of course if someone says that all mountains are hollow, they make a mistake. But it cannot be a conceptual mistake, because either they are asserting that what we conceive of as mountains, defined by other criteria, are in fact always hollow, or they are insisting on hollowness as a new defining characteristic. In the first case, they are clearly making an empirical mistake, attributing some characteristic to mountains that they do not in fact have. In the second case, they are presenting a new conception of mountains focusing on those parts of the physical terrain that have the defining characteristics previously accorded to mountains, but adding hollowness as another necessary condition. This may be objected to on the verbal level ("That's not what we call a mountain.") and very likely on the grounds that it is a concept of something that does not ac- 
tually or only rarely exists. But it cannot be said that it is a false concept for it is hollow, raised spurs of land that the person conceives.

Similarly, the question of whether those creatures we recognize as instances of cows run at 100 m.p.h. is not a conceptual question, but an empirical question about an already clearly defined concept. It only becomes conceptual question, if the suggestion is that running at $100 \mathrm{~m} . \mathrm{p} . \mathrm{h}$. should be part of the definition of a new conception of cow. And there is no correct answer to that, just as there is no correct answer to the question of whether the product of a cross between a cow and a horse, should count as a cow, and horse, or something new. These are matters for human decisions. 7 Take, for example, the panda. Zoologists are unable to decide whether a panda is a species of bear, a species of racoon or sui generis. Perhaps they do not know enough about pandas in which case it is not a conceptual question but an empirical question about how these beasts behave or are physically constituted. But it may be because its characteristics, although all fully accounted for, do not square exactly with those of bears or racoons, despite close similarity. Then I should say that we face a conceptual question, but argue that its classification is a matter of decision. Do we want to modify our concept of bears to include pandas or not? In this sense, notwithstanding logical and empirical restraints, we clearly impose concepts on our world rather than discover them.

When we come to abstract concepts, one problem we face is precisely how to distinguish a conceptual from an empirical question. Things like love and justice, although presumably related to empirical facts about people (such as their drives, feelings and so forth) are clearly created by us in large part. That is to say, our notions of love and justice are the product of a long tradition that has literally invented various ideals and linked them to feelings and drives in an incredibly complex and sophisticated way. When people conceive of themselves as "in love" they are partly conscious of various drives, but they are also relating those drives to a vast network of beliefs about the concept of love. The great difficulty, if you want to know whether this is truly love, is to know what exactly you want to find out. Are you trying to discover whether this desire to be with her will last, whether it is the same kind of desire as other people who claim to be in love experience, or what exactly constitutes this thing called love? If the latter question is one's concern, then one faces a conceptual question, but surely one would be hard pressed to answer it unless one attempted to do so either in terms of a tradition or by regarding it as a question demanding a creative rather than any kind of descriptive response.

The difficulty of disentangling empirical from conceptual questions in relation to abstract concepts has, I suspect, serious implica- 
tions for educational research, since education is itself bound up with many abstract concepts. The sorry story of intelligence testing, for example, or more recently research into effective teaching, is at least partly to be explained by a failure to recognize that as well as empirical questions about what qualities people have, or what consequences various actions have, there are conceptual decisions to be made about what shall be taken to constitute intelligence or being well-educated. Because the conceptual issues are not directly addressed by the researchers themselves, the empirical and the conceptual become confused. In that event, the testing and research surreptitiously produce new conceptions of intelligence and educational success that are scarcely admirable in my view.

One objection that may be raised against my account is that my criteria for sound conceptualization are themselves fluid. The answer to that is that it is obviously true on my account that if you conceive of consistency as, for the sake of example, contradicting yourself, I cannot meaningfully say your conception is incorrect. But what I can say that certain rules of logic cannot be gainsaid, and that what I call "argument," cannot be advanced by contradiction, ignoring implications, and so forth. Again, you can have a different conception of argument, if you insist, and of contradiction, but the fact remains that what I refer to as "argument" cannot proceed in the manner that I label "coherently" by a process of what I refer to as "contradiction". That is a logical truth as certain as that one cannot have square circles.

I shall now turn to the educational implications of the concept of educational finesse. For several hundred years, we have been putting system onto our world. We have sought to organize and categorize experiences, to find out the properties and features of empirical phenomena, to create abstract concepts, and to fashion our drives and desires into systems of value. It might be argued that education is in essence the business of initiating people into this vast achievement, getting them to understand its nature and to be eager to further refine it. If asked why we should value such an undertaking, we might appeal both to the magnificence and the practical utility of the achievement. We might also stress that the ability to make sense of the world, both in the sense of discovering how it is and also to organize it, and to create notions such as morality and love is mankind's distinctive attribute.

But how does one best develop the conceptual finesse in question? Surely through a curriculum based on literature, history, and philosophy. The reason for this is partly their subject matter. I have defined conceptual finesse as going beyond competence in 
specialist areas and concerning itself with the stuff of life, the sorts of human concern that are characteristically the subject matter of non-specialist writers such as historians and philosophers. If people are to be encouraged to think about concepts such as loyalty, love, duty, friendship, or the meaning of life, then they surely need to engage with discourse on such things, and most of the finest discourse is contained in these subjects. But it is also partly to do with methodology or, more accurately, a lack of a narrow, finely-honed methodology. Of course, we do talk about the methods of the historian, competing views of the nature of literary study, and the techniques of the philosopher. But what is characteristic of such developed disciplines as science, mathematics, and even sociology is that they are largely defined in terms of looking for a particular kind of explanation of a particular narrow set of events in a particular way. The so-called cutting edge of science obviously raises and faces some intriguing conceptual questions, but, by and large, the study of science does not involve conceptual probing. Instead, it involves learning a variety of precisely defined concepts, and, in terms of these concepts, learning more and more about the natural world. It does not, except accidentally, touch upon interpreting the world. Something similar is true of sociology for it creates concepts but only for a limited purpose. It explores problems but only from a particular point of view.

Historians, writers, and philosophers by contrast are alike in being concerned with a certain wide ranging subject matter and looking for whatever turns out to be the most appropriate explanation, judgement, justification, or account of various events and ideas. Historians may reasonably be said to be looking for the general in the particular, as Carr argues. 8 But they look at the particular first, and they take to heart the economist Alfred Marshall's injunction that "people must be warned off by every possible means from considering the action of any one cause . . . without taking account of the others whose effects are commingled with it." 9 If they do not, then they are poor historians. By contrast sociologists, qua sociologists, are by definition concerned with a limited kind of explanation of a certain limited sort of situation. When they recognize this and confine themselves to their proper sphere, no damage is done and some understanding is gained. However, their contribution to the development of conceptual finesse in respect of the stuff of life is small. When the limits are not recognized, much damage is done, for we are faced with people who find it difficult to conceive of anything except as a sociological issue.

When people read good literature with understanding, they engage in subtle thoughts about the human condition. Good literature deals with concepts that are the stuff of life and does so with con- 
ceptual finesse. It does not, I believe, weaken the argument to define good literature in this way, thus making the conclusion tautologous. While we will continue to argue about the merit of particular authors on these or any other terms, it surely is the case that a large part of what we mean when we praise a Shakespeare, Iris Murdoch, Graham Greene, William Trevor, Anita Brookner, or Tom Stoppard, is that, notwithstanding vast differences of style, they say something interesting and plausible about human beings. The crucial difference between, say, Iris Murdoch and a psychologist is that the former pursues in depth and with a concern for a wide number of factors, understanding of the particular, while the latter generalizes with concern only for a limited kind of explanation at a cruder level. Of course, what Iris Murdoch has to say about, say, a particular relationship may be implausible or not generalizable, but by and large we do not think that and, when we do, we argue that it is a bad novel. At its best, the novelist provides deeper understanding than the psychologist because she probes deeper in order to understand an event properly before rushing to pontificate on causes. Causes can never be understood without a prior thorough understanding of events and situations. Psychology by its nature seeks to impose explanations on events it has not thoroughly studied. Time and again one can criticize psychologists because of their initial characterisation of events. In other words, one does not so much dispute the finding that $\mathrm{X}$ correlates with $\mathrm{Y}$, as shy away from the too easy and superficial assumption that $X$ and $Y$ are adequate concepts either in themselves or as sufficient to explain particular situations. One does not necessarily dispute that, for example, some studies show that punishment is a less efficacious form of motivation than praise. But one cries out for a satisfactory elucidation of punishment and praise in all their myriad forms, and for a more wide-reaching consideration of other things going on at the same time as the punishment and praise. Above all, we look for a thorough examination of the overall context: what else happened to and what else do we know about the people studied? Some were more motivated by praise, we accept, but were they happy, were they warped, were they well educated, were they inspired and so forth?

In sum, my claim is this that conceptual finesse is a necessary condition of an adequate understanding of a complex and subtle world and that the best examples of it are to be found in the best writers about the human condition, writers, who if they have to be classified, belong in the areas of literature, history and philosophy. Reading such writers is, therefore, likely to be a good route to developing such conceptual finesse. 


\section{Notes}

1The phrase "conceptual finesse" was probably first introduced in my The Philosophy of Schooling (New York: Wiley 1981). In reviewing my Giving Teaching Back to Teachers (Totawa, N.J.: Barnes and Noble, 1984), Robert Dearden wrote "I do wish that he (Barrow) would exercise more conceptual finesse in explaining just what such finesse is. He appears to assume that it it enough to show it."

${ }^{2}$ See, in particular, my "Does the question 'What is education?' make sense?," Educational Theory, 33(3 and 4) 1983. See also Robert B. Nordberg, "Is education real?," John Wilson, "The inevitability of certain concepts (including education)," and my "Misdescribing a cow: The question of conceptual correctness," Educational Theory, 35(2) 1985.

${ }^{3}$ If one has the desire and the ability to make fine discriminations, it may be supposed that during the course of one's life one will do so, and thus acquire a stock of discriminated concepts.

${ }^{4}$ It is thus a degree phrase, as are "happy" and "educated," in that it signifies an ideal state which nobody, in fact, attains. In practice, it is applied to those who attain it to a high degree. See my Happiness and Schooling (Oxford: Martin Robertson, 1980).

${ }^{5}$ One might, of course, equally well see Aristotle as a great discriminator, one who recognized different species within a genus.

${ }^{6}$ On this point, see Richard Pring's sound words in Interpersonal Education (London: Heinemann, 1986).

${ }^{7}$ See "Misdescribing a cow," op. cit..

${ }^{8}$ E. H. Carr, What is history? (London: Macmillan, 1961.

${ }^{9}$ A. C. Pigou (Ed.), Memorials of Alfred Marbhall (London: Macmillan, 1925. 